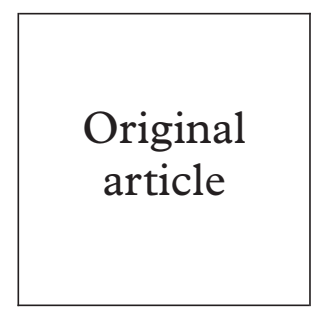

\title{
Incidence of recurrent diagnoses of Chlamydia trachomatis genital infections among male and female soldiers of the US army
}

\author{
Scott D Barnett, John F Brundage
}

Background/objectives: Few studies of Chlamydia trachomatis incidence, especially among men, and most studies of $C$ trachomatis in US military populations are cross sectional prevalence surveys. A population based retrospective cohort was used to determine risk factors for repeat diagnoses of genital $C$ trachomatis infections among male and female soldiers with previous $C$ trachomatis infections.

Methods: All active duty soldiers diagnosed with $C$ trachomatis genital infections between 1994 and 1998. Cohort members were passively followed until repeat diagnoses of $C$ trachomatis infection, termination of army service, or the end of the study.

Results: Among 11771 soldiers with initial diagnoses of chlamydia, the crude rate of repeat diagnoses was 52.0 per 1000 person years. Women and men aged 20-24 were at greatest unadjusted risk of reinfection. After adjustment, women aged 20-24 and men aged 25-29 were at higher risk than their younger or older counterparts.

Conclusions: Results of this study suggest that both male and female soldiers who are diagnosed with chlamydia infections have relatively high risks of reinfection through their $20 \mathrm{~s}$.

(Sex Transm Inf 2001;77:33-36)

Keywords: epidemiology; military personnel; sexually transmitted diseases; United States

\section{Introduction}

Chlamydia trachomatis is the most common bacterial cause of sexually transmitted diseases in the United States. ${ }^{1-4}$ In the United States in 1997, it was estimated that 335.8 and 70.4 per 100000 women and men, respectively, were infected with chlamydia. ${ }^{15}$ While more than half of a million cases were reported in 1997, it was estimated that nearly five times as many cases were asymptomatic and undetected. ${ }^{1{ }^{2}}$ Thus, the annual incidence of new chlamydia infections in the United States is approximately three million..$^{2-4}$ Costs associated with genital $C$ trachomatis infections (for example, urethritis, cervicitis, epididymitis, salpingitis, pelvic inflammatory disease (PID), infertility, neonatal conjunctivitis, and pneumonia) are estimated to exceed $\$ 2$ billion annually. ${ }^{3}$

Chlamydia studies in US military populations have generally focused on infection prevalences in selected subgroups. For example, Brodine and colleagues studied asymptomatic active duty members of the US navy and marines. Infections were detected in $4.1 \%$ and $4.5 \%$ of male and female survey participants, respectively. ${ }^{6}$ Gaydos and colleagues documented chlamydia infections in $9.2 \%$ of new female recruits at a large US army basic training post. ${ }^{7}$ Catterson and Zadoo documented chlamydia infections in $8.2 \%$ of 476 asymptomatic female soldiers who presented to a troop medical clinic for routine Papanicolaou smears. $^{8}$

The Armed Forces Epidemiological Board recommends all new female accessions undergo chlamydia screening, preferably within the recruit training period but screening within the first year is acceptable. Existing female military service members should be screened routinely for chlamydia at the time of each recommended Papanicolaou smear until age 25, with further screening to be dictated by symptoms or risk factors. Chlamydia screening for male personnel is recommended at any medical encounter as indicated by symptoms or risk factors.

While prevalence surveys are useful for characterising the burden of $C$ trachomatis infections in surveyed subgroups, they are not informative regarding the dynamics of its spread (that is, rates of and risk factors for acquiring new infections). There have been few studies, however, and none in US military populations, that have documented incident (as opposed to prevalent) chlamydia infection rates and risk factors. For this study, a cohort of active duty soldiers who were previously diagnosed with (and presumably effectively treated for) $C$ trachomatis infections were passively followed to assess incidence rates of and correlates of risk of repeat $C$ trachomatis diagnoses.

\section{Methods}

DATA SOURCES

The Defense Medical Surveillance System (DMSS) is the central resource of the US Department of Defense for medical surveillance of active duty service members. The DMSS is operated by the Army Medical Surveillance Activity. On a regular basis, the DMSS receives, validates, and integrates in a relational database system personnel, hospitalisation, ambulatory visit, and reportable events data relevant to all active members of the US
Accepted for publication 14 November 2000 


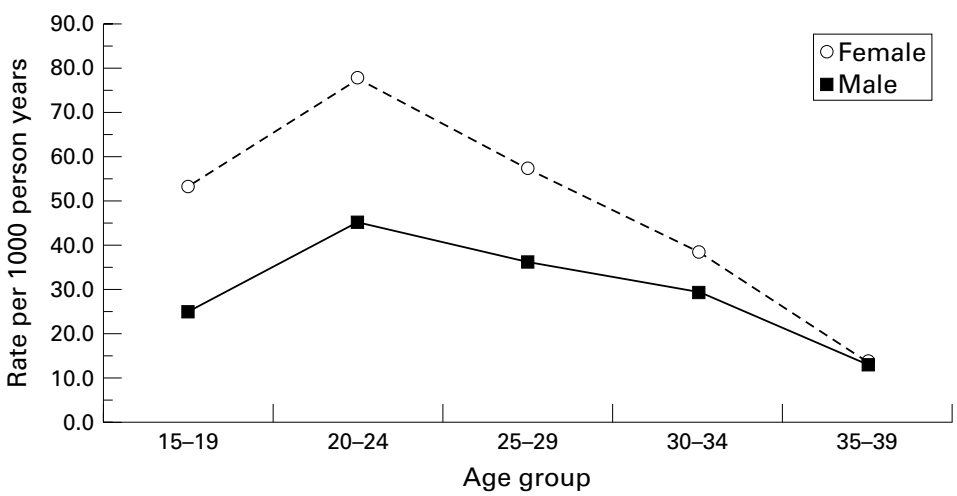

Figure 1 Age and sex specific rates of repeat diagnoses of $C$ trachomatis infections, US army.

armed services. On a monthly basis, files that list all individuals on active duty (including demographic and military characteristics of each individual) are transmitted from the Defense Manpower Data Center, Seaside, California, to the DMSS. Also, since 1994, there has been an armywide requirement to report all cases of approximately 70 medical conditions (based on their public health, political, and/or military operational importance) to the Army Medical Surveillance Activity for inclusion in the DMSS. $C$ trachomatis genital infections are among the army's required reportable medical events.

\section{STUDY DESIGN}

The study was a passive retrospective follow up of a cohort of active duty US army soldiers. Active duty soldiers were passively entered into a study cohort on the 30th day after the first report of a laboratory confirmed (Transcription Mediated Amplification, Gen-Probe, San Diego, CA, USA) $C$ trachomatis genital infection (ICD-9-CM “099.41") during the period 1 January 1994 to 31 December 1998 . Cohort members were tested for $C$ trachomatis as a

Table 1 Frequencies and incidence rates of repeat diagnoses of genital $C$ trachomatis infections during follow up of a cohort of previously infected US army soldiers, 1994-Fuly 1999

\begin{tabular}{|c|c|c|c|c|}
\hline & $\begin{array}{l}\text { Incident cases } \\
(\%)\end{array}$ & $\begin{array}{l}\text { Person years of } \\
\text { follow up }\end{array}$ & $\begin{array}{l}\text { Repeat } \\
\text { diagnoses (per } \\
1000 \text { person } \\
\text { years) }\end{array}$ & $\begin{array}{l}\text { Rate ratio (RR) } \\
(95 \% \mathrm{CI})\end{array}$ \\
\hline Overall & 879 & 16903.26 & 52.00 & - \\
\hline \multicolumn{5}{|l|}{ Sex } \\
\hline Female & $557(63.4)$ & 8466.44 & 65.79 & $1.72(1.50-1.98)$ \\
\hline Male & $322(36.6)$ & 8436.81 & 38.17 & 1.00 \\
\hline \multicolumn{5}{|l|}{$\mathrm{Age}^{\star}$} \\
\hline$<20$ & $134(15.2)$ & 3023.29 & 44.32 & $3.50(1.54-7.93)$ \\
\hline $20-24$ & $557(63.4)$ & 9002.21 & 61.87 & $4.89(2.19-10.92)$ \\
\hline $25-29$ & $146(16.6)$ & 3285.18 & 44.44 & $3.51(1.55-7.94)$ \\
\hline $30-34$ & $36(4.1)$ & 1118.82 & 32.18 & $2.54(1.07-6.03)$ \\
\hline $35+$ & $6(0.7)$ & 473.75 & 12.66 & 1.00 \\
\hline \multicolumn{5}{|l|}{ Race } \\
\hline Black & $558(63.5)$ & 9831.40 & 56.76 & $1.17(0.92-1.47)$ \\
\hline White & $240(27.3)$ & 5406.42 & 44.39 & $0.91(0.71-1.17)$ \\
\hline Other & $81(9.2)$ & 1665.43 & 48.64 & 1.00 \\
\hline \multicolumn{5}{|l|}{ Marital status } \\
\hline Married & $234(26.7)$ & 5631.84 & 41.55 & $0.87(0.62-1.23)$ \\
\hline Single & $607(69.1)$ & 10474.08 & 57.95 & $1.22(0.88-1.69)$ \\
\hline Other & $38(4.3)$ & 797.34 & 47.66 & 1.00 \\
\hline \multicolumn{5}{|l|}{ Military rank (grade) $\dagger$} \\
\hline PVT (E1-E2) & $152(17.3)$ & 3969.69 & 38.29 & $1.27(1.00-1.62)$ \\
\hline PFC-CPL (E3-E4) & $613(69.7)$ & 9147.45 & 67.01 & $2.22(1.82-2.72)$ \\
\hline SGT-LTC (E5-O5) & $114(12.9)$ & 3784.52 & 30.12 & 1.00 \\
\hline
\end{tabular}

${ }^{\star}$ Mean ages: women $=22.46$ years, men $=23.77$ years .

tGrades E1-E4 approx $\$ 11520$ to $\$ 17820$; grades E5-O4, $\$ 18168$ to $\$ 40716$ per annum (1998 US\$). result of symptoms, part of a routine gynaecological examination, or named a potential infectious contact. Each member of the cohort was passively followed from the time of entry in the cohort until (a) a study end point; (b) death, retirement, or discharge from military service before the end of the study (a censoring event); or (c) the end of the study (a censoring event). End points were defined as the first reports of $C$ trachomatis infections of cohort members during follow up. The end of the study was 15 July 1999.

Exposure to risk was quantified in terms of person time of follow up. Person time was calculated as the time from enrolment in the follow up cohort until an end point or censoring event. Incidence rates were calculated by dividing the number of end points per stratum by the appropriate stratum specific person time estimates.

Cox proportional hazards models were used to calculate hazard ratios (HR) and 95\% confidence intervals (CI) while controlling for effects of potentially confounding factors. Variables considered in both unadjusted and adjusted models were age, race, marital status, and military rank (at the time of entry in the cohort). All analyses were carried out using SAS (Ver 6.12, Carey, NC, USA).

\section{Results}

CHARACTERISTICS OF THE FOLLOW UP COHORT Between 1 January 1994 and 31 December 1998, 12800 cases of $C$ trachomatis were reported among 11771 active duty soldiers. Because repeat diagnoses within a 30 day period were considered to be recurring infections, 1193 repeat diagnoses among 1057 active duty personnel were excluded. The experience of these soldiers following presumably effective treatments of their $C$ trachomatis infections formed the study base. Approximately half $(49.6 \%)$ of the cohort's members were males. Soldiers who were black nonHispanic $(56.3 \%)$, never married $(65.7 \%)$, or high school graduates or less $(95.2 \%)$ were also overrepresented among cohort members in relation to the army overall. The median ages of cohort members (at the time of their first reported $C$ trachomatis infections) were 21.5 years (range 16.6-50.9) and 22.9 years (range 17.1-48.8) for females and males, respectively. Ninety one per cent of all cohort members were based in the continental United States; $68 \%$ of those were in the southern United States (Alabama, Arkansas, Delaware, Washington DC, Florida, Georgia, Kentucky, Louisiana, Maryland, Mississippi, North Carolina, Oklahoma, South Carolina, Tennessee, Texas, Virginia, West Virginia).

\section{RECURRENCE INCIDENCE RATES}

A total of 879 cohort members had repeat diagnoses of genital $C$ trachomatis infections during variable periods of follow up. The cumulative incidence of repeat diagnoses during follow up was $7.5 \%$, and the crude rate of repeat diagnoses was 52.00 per 1000 person years. Crude rates of repeat diagnoses were higher among females than males in all age 
Table 2 Risk factors and 95\% CI for repeat diagnoses of C trachomatis infections among active duty US army personnel, 1994-Fuly 1999

\begin{tabular}{|c|c|c|c|c|c|c|c|c|}
\hline & \multicolumn{4}{|c|}{ Female } & \multicolumn{4}{|l|}{ Male } \\
\hline & \multicolumn{2}{|c|}{ Unadjusted } & \multicolumn{2}{|c|}{ Adjusted $t$} & \multicolumn{2}{|c|}{ Unadjusted } & \multicolumn{2}{|c|}{ Adjusted $\dagger$} \\
\hline & $H R^{\star}$ & $95 \% C I$ & $H R$ & $95 \% C I$ & $H R$ & $95 \% C I$ & $H R$ & $95 \% C I$ \\
\hline \multicolumn{9}{|l|}{ Age group } \\
\hline $30+$ & 1.00 & - & 1.00 & - & 1.00 & - & 1.00 & - \\
\hline $25-29$ & 1.73 & $1.02-2.93$ & 1.49 & $0.89-2.57$ & 1.50 & $0.95-2.36$ & 1.22 & $0.76-1.97$ \\
\hline $20-24$ & 2.35 & $1.44-3.82$ & 1.79 & $1.04-3.08$ & 1.77 & $1.16-2.68$ & 1.07 & $0.64-1.79$ \\
\hline$<20$ & 1.56 & $0.94-2.60$ & 1.16 & $0.65-2.07$ & 1.00 & $0.95-2.36$ & 0.54 & $0.28-1.03$ \\
\hline \multicolumn{9}{|l|}{ Race } \\
\hline White & 1.00 & - & 1.00 & - & 1.00 & & 1.00 & - \\
\hline Black & 1.10 & $0.93-1.30$ & 1.13 & $0.94-1.32$ & 1.75 & $1.38-2.22$ & 1.82 & $1.43-2.31$ \\
\hline \multicolumn{9}{|l|}{ Marital status } \\
\hline Married & 1.00 & - & 1.00 & - & 1.00 & - & 1.00 & - \\
\hline Single & 1.10 & $0.92-1.31$ & 1.05 & $0.86-1.27$ & 1.53 & $1.21-1.94$ & 1.49 & $1.13-1.96$ \\
\hline \multicolumn{9}{|l|}{ Military rank $\ddagger$} \\
\hline SGT-MAJ (E5-O4) & 1.00 & - & 1.00 & - & 1.00 & - & 1.00 & - \\
\hline PVT-CPL (E1-E4) & 1.66 & $1.24-2.24$ & 1.47 & $1.04-3.08$ & 1.57 & $1.20-2.06$ & 1.51 & $1.06-2.14$ \\
\hline
\end{tabular}

${ }^{\star} \mathrm{HR}=$ hazard ratio, $\mathrm{CI}=$ confidence interval.

¥Grades E1-E4 approx $\$ 11520$ to $\$ 17820$; grades E5-O4, $\$ 18168$ to $\$ 40716$ per annum (1998 US\$).

categories (fig 1). Among both males and females, crude rates peaked in the early $20 \mathrm{~s}$ (females: 77.98 per 1000 person years; males: 45.30 per 1000 person years) and declined with age thereafter. Single and black cohort members had higher crude rates of repeat diagnoses than their counterparts (table 1). One hundred and thirty personnel were diagnosed with at least two repeat genital $C$ trachomatis infections.

SURVIVAL ANALYSIS

Among female cohort members, the strongest independent predictors of repeat diagnosis risk were age and grade. With control of effects of other factors, females in their 20s had higher risks of repeat diagnosis than those younger or older. Females in their early 20s (the highest risk age group) were $79 \%$ more likely to have repeat $C$ trachomatis diagnoses than those older than 30 (the lowest risk age group) (table 2). Other than age, the strongest independent correlate of repeat diagnosis among females was junior enlisted grade $\left(R_{\mathrm{adj}}=1.66\right.$, versus senior enlisted or officer). Of note, marital status and race were not significant correlates of repeat diagnosis among females.

Among male cohort members, repeat diagnosis risks increased with age through the 20 s and declined with age thereafter. Males in their late 20 s (the highest risk age group) were more than twice $\left(R_{\mathrm{adj}}=2.26\right)$ as likely as teenagers (the lowest risk age group) to have repeat $C$ trachomatis diagnoses. Other than age, the strongest independent correlates of repeat diagnoses among males were black race $\left(R R_{\mathrm{adj}}=1.82\right.$, versus white $)$, single marital status $\left(R_{\mathrm{adj}}=1.49\right.$, versus married), and junior enlisted grade $\left(R_{\mathrm{adj}}=1.51\right.$, versus senior enlisted or officer) (table 2 ).

\section{Discussion}

Throughout history, sexually transmitted infections (STIs) have caused significant morbidity among soldiers. ${ }^{9}{ }^{10}$ It is difficult, however, to characterise risk factors for acquiring STIs during military service since prevalent infections may be asymptomatic and thus undetected for long periods. In addition, the US military services receive recruits from every geographic region of the United States and from a broad spectrum of sociodemographic backgrounds, and while on active duty, service members are stationed at or temporarily deployed to numerous locations around the world. Thus, when infections are diagnosed, the times, locations, and circumstances of their acquisitions are often indeterminable. Since many prevalent infections were acquired before service or at unknown times during service, incidence data are necessary to assess rates of and to characterise risk factors for acquiring genital chlamydia infections among soldiers.

The objectives of the study were to estimate rates and demographic correlates of risk of recurrent $C$ trachomatis infections among active duty US army soldiers. We initiated follow ups of previously infected cohort members 30 days after their initial diagnoses to allow for full treatment effects, appropriate follow ups, and retreatments if necessary. Although an assumption of cure 30 days after initial diagnoses may have been justified based on the universal availability of cost free medical care, the ease of delivery of effective treatments, and the generally aggressive management of STIs by military medical staffs, we refer to end points of the study as "repeat diagnoses" rather than as "recurrent infections."

Studies among females have generally found that $C$ trachomatis prevalences and reinfection risks were highest among teenagers and declined with age thereafter. ${ }^{71-14}$ In addition, a recent large cross sectional survey of female army recruits found that black race was a significant predictor of prevalent $C$ trachomatis infection. ${ }^{7}$ In contrast, in this study, females in their 20s had higher risks of repeat diagnoses than those in their teens, and race was not a strong risk correlate. Many factors could account for these differences. For example, this study was population rather than STD clinic based. In general, teenaged females who are treated at STD clinics in large urban areas, for example, may not be comparable with teenagers in active military service. In addition, when some young females enter military service, they may move from relatively high (for example, 
hyperendemic "core" neighbourhoods) to lower STI risk circumstances. ${ }^{15}$ Finally, females in the army may be more responsive to STI counselling and prevention.

There have been remarkably few studies of chlamydia genital infection incidence among men. In this study in which nearly half of the subjects were men, male soldiers who were single, black, and in their late 20 s had increased risks of repeat diagnoses relative to their counterparts. Recent cross sectional surveys among females in military service led to the recommendation that recruits younger than 25 years old should be routinely screened. Findings of the current study suggest that since soldiers have relatively high rates of recurrent infections through their $20 \mathrm{~s}$, as a minimum, there should be counselling and follow up testing of all men and women (regardless of age) after documented chlamydia infections.

Results of the study should be interpreted carefully. For example, the study followed only soldiers with initial diagnoses of $C$ trachomatis infections. As a result, findings from follow up of this relatively "high risk" cohort may not be generalisable to other military service members. Also, it is unlikely that all initial infections were eradicated by treatment. ${ }^{16}$ As a result, some persistent "initial" infections were probably included among "repeat" diagnoses. In addition, study end points were ascertained from notifiable medical event case reports (which are less than 100\% sensitive) and censoring occurred without active assessments of $C$ trachomatis infection status. As a result, there was undoubtedly underascertainment of end points among cohort members. Finally, screening and diagnostic tests for genital $C$ trachomatis infections vary widely in their operating characteristics. ${ }^{17}$ As a result, in this study, some true infections were undoubtedly "missed" owing to relatively insensitive test modalities, materials, and/or procedures. In consideration of the study's characteristics overall, we believe that point estimates of rates of repeat diagnoses from the study should be considered lower bound estimates of actual recurrent infection rates.

Relative risk estimates derived from the study should also be interpreted cautiously. To control for possible sex related differences in end point ascertainment (for example, clinical manifestations of genital infections, routine screening practices), analyses were conducted separately among males and females. In relation to military rank, there are perceived incentives for senior enlisted soldiers and officers to seek care of STIs outside of the military medical system. Since the study was restricted to soldiers who were the subjects of recent chlamydia case reports, it seems likely that most if not all repeat diagnoses would also be reported. Still, relative risks associated with junior enlisted grade may be overestimated due to more complete ascertainment and reporting of their infections. Finally, since medical care is free and accessible to all soldiers regardless of age, race/ethnicity, and marital status, the directions and magnitudes of risks associated with these factors seem likely to be valid.

In conclusion, this study is the first to attempt to estimate $C$ trachomatis infection rates and risk factors in a population of US military service members, and it is one of only a few studies to include significant numbers of males. Results of the study suggest that both male and female soldiers have relatively high risks of recurrent chlamydia infections through their 20s. The findings extend insights gained from cross sectional surveys in military populations. They should be considered during the development and implementation of military screening, treatment, and prevention practices.

The authors thank Joel Gaydos, MD, MPH, for his thoughtful review and helpful comments.

The views expressed are the private views of the authors, and they do not necessarily reflect official views of the US Army or the Department of Defense.

1 Stamm WE. Chlamydia trachomatis infections: progress and problems. F Infect Dis 1999;179(Suppl 2):S380-3.

2 Groseclose SL, Zaidi AA, DeLisle SJ, et al. Estimated incidence and prevalence of genital Chlamydia trachomatis
infections in the United States, 1996. Sex Transm Dis 1999; 26:339-44

3 Washington AE, Johnson RE, Sanders LL, et al. Incidence of Chlamydia trachomatis infections in the United States: using reported Neisseria gonorrhoeae as a surrogate. In: Oriel D, Ridgway G, Schachter J, et al, eds. Chlamydial infections. Cambridge: Cambridge University Press, 1986: 487-90.

4 Cates, W, and the American Social Health Association Panel. Estimates of the incidence and prevalence of sexually transmitted diseases in the United States. Sex Transm Dis 1999;26(suppl):S2-7.

5 National Institutes of Health. Chlamydial infection. National Institute of Allergy and Infectious Diseases. Fact Sheet. Available from URL: http://www.niaid.nih.gov/factsheets/ stdclam.htm. Last updated June 1998.

6 Brodine SK, Shafer MA, Shaffer RA, et al. Asymptomatic sexually transmitted disease prevalence in four military populations: application of DNA amplification assays for Chlamydia and gonorrhea screening. F Infect Dis 1998;178: 1202-4.

7 Gaydos CA, Howell MR, Pare B, et al. Chlamydia trachomatis infections in female military recruits. $N$ Engl $\mathcal{F}$ Med 1998;339:739-44.

8 Catterson ML, Zadoo V. Prevalence of asymptomatic chlamydial cervical infection in active duty army females. Mil Med 1993;158:618-9.

9 Kampmeier RH. Venereal diseases in the United States army: 1775-1900. Sex Transm Dis 1982;9:100-3.

10 Emerson LA. Sexually transmitted diseases control in the armed forces, past and present. Mil Med 1997;162:87-91.

11 Hillis SD, Nakashima A, Marchbanks PA, et al. Risk factors for recurrent Chlamydia trachomatis infections in women.

12 Fortenberry JD, Brizendine EJ, Katz BP, et al. Subsequent sexually transmitted infections among adolescent women with genital infection due to Chlamydia trachomatis, Neisseria gonorrhoeae, or Trichomonas vaginalis. Sex Transm Dis 1999;26:26-32.

13 Richey CM, Macaluso M, Hook EW. Determinants of reinfection with Chlamydia trachomatis. Sex Transm Dis 1999; 26:4-11.

14 Michelson KN, Thomas JC, Boyd C, et al. Chlamydia rachomatis infection in a rural population: the importance of screening men. Int $\mathcal{F}$ STD AIDS 1999;10:32-7.

15 Zenilman JM, Ellish N, Fresia A, et al. The geography of sexual partnerships in Baltimore: applications of core
theory dynamics using a geographic information system. Sex Transm Dis 1999;26:75-81.

16 Somani J, Bhullar VB, Workowski KA, et al. Multiple drugresistant Chlamydia trachomatis associated with clinical resistant Chament failures. F Infect Dis 2000;181:1421-7.

17 Marrazzo JM, White CL, Krekeler B, et al. Communitybased urine screening for Chlamydia trachomatis with a igase chain reaction assay. Ann Intern Med 1997;127:796803 . 


\section{LETTERS TO THE EDITOR}

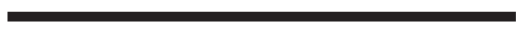

\section{Chlamydial infections in children}

EdIToR,- -We know that Chlamydia trachomatis infections (serovars $\mathrm{D}-\mathrm{K}$ ) are a significant cause of morbidity in the adult population, particularly young women. This justifies the considerable efforts and costs of preventing, diagnosing, and treating chlamydial infections. It is also well established that $C$ trachomatis can cause conjunctivitis and pneumonitis in neonates and infants as a result of vertical transmission.

There is no doubt that symptomatic children should be treated but should we also treat asymptomatic carriers? What would be the benefit of treating asymptomatic children of mothers who were proved or have a history suggestive of $C$ trachomatis infection during their pregnancy? Should we treat these children systematically? Up to what age? These questions have recently arisen in our department after the diagnoses of $C$ trachomatis conjunctivitis in several small children.

The American guidelines for the management of sexually transmitted infection ${ }^{1}$ do not recommend prophylactic treatment to infants of chlamydia positive mothers but close clinical supervision and treatment if symptoms develop. These guidelines do highlight the importance of antenatal screening as the main preventive measure in the vertical transmission of $C$ trachomatis. Routine prophylaxis with silver nitrate or topical antibiotics would not prevent $C$ trachomatis transmission. Neither the UK national guidelines nor the SIGN (Scottish Intercollegiate Guidelines Network) guidelines ${ }^{2}{ }^{3}$ address the issue.

In preadolescent children sexual abuse should always be considered when a diagnosis of $C$ trachomatis has been made, although there are reports of perinatally transmitted infections up to the age of $3^{4}$ and in our department a family cluster of $C$ trachomatis infection has recently been reported, including a 6 year old girl in whom there was no evidence of sexual abuse. ${ }^{5}$

We await with interest the results of the pilot chlamydial screening projects in Portsmouth and the Wirral but suggest that routine antenatal screening for $C$ trachomatis infections with a nuclear amplification test (NAT) would reduce perinatal and infant morbidity and possible infection in children, whether symptomatic or not. At the very least, targeted antenatal screening of higher risk groups (young pregnant women up to 25 , or those with new or multiple partners, as recommended by the American guidelines) should be clearly specified in the current UK guidelines.

A negative reliable chlamydial test documented during a pregnancy would make a diagnosis of $C$ trachomatis infection in a child less likely to be of vertical perinatal transmission.

In the meantime, what should we do? Investigating and treating asymptomatic children as "contacts" may cause unnecessary anxiety and unpleasantness to both child and parents. Epidemiological antibiotic treatment is not exempt of risks to the individual patient and is likely to increase resistance in the general population.

We would welcome the view of clinicians and thus perhaps open a debate in an area of sexually transmitted infections in which not much is known.

C OROZ K A M PORTER-BOVERI C THOMPSON

Department of Genito-Urinary Medicine, Victoria Hospital, Hayfield Road, Kirkcaldy, Fife KY2 5AH,

Correspondence to: Dr Oroz

1 Centres for Disease Control and Prevention. Guidelines for treatment of sexually transmitted Guidelines for treatment of sexually transmitted
diseases. Atlanta, GA: US Department of diseases. Atlanta, GA: Ur Department

2 UK national guidelines on sexually transmitted infections and closely related conditions, sexuinfections and closely related conditions, sexu-
ally transmitted infections. $\mathcal{F}$ Sex Health HIV ally transmitted in
$1999 ; 75$ (Suppl 1).

3 Scottish Intercollegiate Guidelines Network. Management of genital chlamydia trachomatis infection. National Clinical Guideline. March 2000, Pub No 42.

4 Schachter J, Grossman M, Sweet RL, et al. Prospective study of perinatal transmission of Chlamydia trachomatis. ЭAMA 1986;255: 3374-7.

5 Thompson C, Macdonald M, Sutherland A. A family cluster of Chlamydia trachomatis infection. BMF 2001;322:1473-4.

Accepted for publication 30 August 2001

\section{Self treatment among a sample of first time attenders at a genitourinary medicine clinic}

EDIToR,-Many people self medicate or seek advice from others before attending a medical consultation and while this has been documented for a number of conditions, there is little reason to suppose the behaviour will be different for a sexually transmitted infection (STI). There may be specific problems with self medication for STIs since they may mask signs and symptoms and unprescribed use of antibiotics may select for resistance among strains of Neisseria gonorrhoeae and other bacteria residing within and outside the genital tract. ${ }^{1}$ We examined all aspects of self care in a sample of first time attenders at a GUM clinic in the United Kingdom. There were 492 consecutive first time attenders in a 3 month period, of which we achieved the participation of 188 clients (128 females, 60 males).

Information was collected via structured interview carried out by a health adviser. We asked about a range of issues concerning treatment seeking and symptoms experienced by clients. We specifically asked clients what measures they had taken between suspecting an STI and attending the clinic. Forty four respondents (23\%) reported using a medication or remedy before attending the clinic. A total of 80 remedies were mentioned. The most commonly reported treatment was the use of Canesten $(n=15)$, followed by paracetamol $(n=5)$, antibiotics $(n=5)$, Diflucan $(n=3)$, and unspecified pessaries $(n=3)$. Sixteen other medications were reported, of which 12 were identified by brand name. Two respondents (one on the recommendation of her mother) reported drinking lemon barley water and one drank cranberry juice. One person drank more water than usual, another drank less. Avoiding milk and bread, eating live yoghurt, and taking bicarbonate of soda were all mentioned by at least one respondent. Most medications were acquired either from the chemist or from trusted others; these latter included a wife, a sister, two friends, and two mothers.

These findings fit well with data from other countries and support a large US study. ${ }^{2}$ The wide range of self treatments attests to the lack of knowledge about what might or might not "work" as a treatment for the symptoms of a sexually transmitted infection. The very large number of named "products" is striking. Remedies involving changing eating and drinking patterns are fairly common and are usually the consequence of advice from others. Given the stigma associated with having a suspected STI it is not surprising that only a few respondents discussed their treatment strategy with others.

It is important that genitourinary clinic staff recognise that a significant proportion of people attending will have tried some form of self medication. It would be desirable to establish which products have been tried and how recently. There is also an opportunity here for offering advice and education for the future and ensuring that there is good understanding of the role of antibiotics.

M K PITTS

$S$ CANNON

G SINGH

Australian Research Centre, sex, Health E Society, La Trobe University, 215 Franklin Street, Melbourne, Victoria 3000, Australia

Correspondence to: Professor Pitts

m.pitts@latrobe.edu.au

1 Gordon SM, Mosure DJ, Lewis J, et al. Prevalence of self-medication with antibiotic among patients attending a clinic for treatment of sexually transmitted diseases. Clin Infect Dis 1993;17:462-5.

2 Irwin D, Thomas JC, Spitters CE, et al. Self-treatment patterns among clients attending sexually transmitted disease clinics and the effect of self treatment on STD symptom duration. Sex Transm Dis 1997;24:6:372-7.

Accepted for publication 30 August 2001

\section{Circumcision and STD in the United} States

EDIToR,-The study by Diseker $e t a l,{ }^{1}$ though examining too small a study population to obtain statistically meaningful results in some aspects, is commendably objective. Their study tends to confirm previous research findings relative to circumcision versus syphilis and gonorrhoea, the majority of which indicate a strong (protective) relation between the non-circumcised state and syphilis and a weaker relation with gonorrhoea.

A brief examination of this and several previous studies going back 150 years on circumcision versus syphilis and gonorrhoea reveals an intriguing relation: syphilis is proportionally lower in circumcised men than it is in uncircumcised men.

In 1855, Hutchinson, ${ }^{2}$ in England, reported a syphilis:gonorrhoea ratio of 0.23:1 for Jews and 1.54:1 for non-Jews (all ratios in this letter are my re-expressions of the original data). In 1934 Wolbarst, ${ }^{3}$ a NY urologist examining 1500 cases, reported a ratio of syphilis and chancroid to gonorrhoea of $0.36: 1$ for circumcised men and 0.78:1 for uncircumcised men (only 5-25\% of American men were routinely circumcised in the late 19 th century/early 20 th century) ${ }^{4}$ I note from Diseker et al's table 2 (Cross section analysis at baseline) that the ratio of syphilis to gonorrhoea is $0.06: 1$ in circumcised men 
and 0.09:1 for uncircumcised men, while Table 4 (Cohort analysis-new STD) reveals 0.07:1 for circumcised men and 0.11:1 for uncircumcised men.

While the foregoing is obviously a very limited statistical analysis and other factors may play a part, it is nevertheless fascinating to see the consistently lower syphilis:gonorrhoea ratio in circumcised men, indicating a potential protective effect by circumcision against syphilis far more so than against gonorrhoea. Secondly, the syphilis:gonorrhoea ratio would appear to have decreased dramatically over time, which raises a question: if circumcision is more effective against syphilis than it is against gonorrhoea and considering the popularity of neonatal circumcision in the United States over many decades, would we not expect-ceteris paribus - to see in time a general decrease in the United States of syphilis in both relative and absolute terms?

I would encourage Diseker and colleagues to follow up their interesting study with further research on a larger scale into the relation between circumcision and STDs in order to establish more precisely the degree of protection, if any, afforded by circumcision as a prophylactic health measure.

STEFAN A BAILIS

Research and Education Association on Circumcision Health Effects, Bloomington, MN, USA

sabailis@mindspring.com

1 Diseker RA, Perman TA, Kamb ML, et al. Circumcision and STD in the United States: cross sectional and cohort analysis. Sex Transm Inf 2000;76:474-9.

2 Hutchinson J. On the influence of circumcision in preventing syphilis. Medical Times $\mathcal{E}$ Gazette in preventing syp

3 Wolbarst AL. Does circumcision in infancy protect against disease? Virginia Med Monthly tect against disea
1934;61:723-8.

4 Wallerstein E. Circumcision, an American health fallacy. NewYork: Springer, 1980.

Accepted for publication 20 July 2001

\section{Hepatitis B and C seroprevalence in Novosibirsk, western Siberia}

EDITOR,-Chronic liver disease represents one of the major public health problems in Western countries. Hepatitis B and C viruses are becoming the main causes of cirrhosis and primary liver carcinoma. Hepatitis C virus (HCV) accounts for approximately $20 \%$ of cases of acute hepatitis, $70 \%$ of chronic hepatitis, and $30 \%$ of end stage liver disease in the United States. ${ }^{1}$ Today, injecting drug use and high risk sexual activity are the most frequently identified risk factors associated with $\mathrm{HCV}$ infection. ${ }^{2}$ Likewise, in areas of high endemicity of hepatitis B virus (HBV), perinatal transmission is the main route of transmission, whereas in areas of low endemicity, sexual contact among high risk adults is predominant. $^{3}$

Epidemiology of viral hepatitis is studied mostly in blood donors and patients; however, it is unknown whether donors represent

Table 1 Prevalence rates of $\mathrm{HBs} \mathrm{Ag}$ and anti-HCV antibodies among various population groups

\begin{tabular}{lllllll}
\hline Group & No & $\begin{array}{l}\text { Mean age } \\
\text { (years) (SD) }\end{array}$ & $\begin{array}{l}\text { M/F } \\
(\%)\end{array}$ & $\begin{array}{l}\text { HBsAg } \\
(\%)\end{array}$ & $\begin{array}{l}\text { HCV } \\
(\%)\end{array}$ & $\begin{array}{l}\text { Both markers } \\
(\%)\end{array}$ \\
\hline School & 423 & $15.5(0.1)$ & $43 / 57$ & 2.1 & 2.6 & 0.2 \\
Medical college & 103 & $19.4(0.1)$ & $9 / 91$ & 0 & 2.9 & 0 \\
Medical university & 173 & $21.4(0.2)$ & $23 / 77$ & 3.5 & 6.4 & 0.6 \\
Adults & 374 & $42.0(0.5)$ & $43 / 57$ & 2.4 & 5.3 & 0.8 \\
Donors & 4552 & NA & $66 / 34$ & 1.1 & 2.1 & NA \\
\hline
\end{tabular}

$\mathrm{NA}=$ data not available.

the general population. The prevalence of viral hepatitis among children and adolescents is rarely investigated. However, in Italy the highest incidence of new hepatitis B cases (approximately 10 in 100 000) currently occurs in subjects between 15 and 24 years of age, ${ }^{4}$ and in Russia young adults aged 15-29 account for $70-80 \%$ of acute viral hepatitis cases. $^{5}$

The aim of the present study was to evaluate the occurrence of HBV and HCV markers among various population groups of Novosibirsk (western Siberia), Russia. Novosibirsk is the largest city in Siberia and the third one in Russia, with a population of approximately 1.4 million. The following groups of participants were examined in 1995-9:

- A random representative sample of adult population aged 25-64 years (161 males, 213 females).

- A random representative sample of school students aged $14-17$ years (170 males, 226 females).

- Students of medical college aged 18-29 years (9 males, 94 females).

- Students of medical university (IV-VI grades) aged 17-31 years (40 males, 133 females).

- Blood donors (4552 people).

The study was approved by the local ethics committee, and each participant gave informed consent. HBsAg and anti-HCV antibodies were tested in serum samples using previously validated second generation ELISA kits ("Vector-Best," Novosibirsk, Russia).

The prevalence rates of viral hepatitis $B$ and $\mathrm{C}$ markers among various population groups are shown in table 1 . Prevalence of HBsAg and anti-HCV antibodies among general adult population was twice as high as in blood donors. Among schoolchildren, no difference was found between males and females. In adults, HCV was detected more frequently in males compared with females $(8.2 \%$ and $3.3 \%$ respectively, $\mathrm{p}<0.05)$. The association of both infections were found in $0.8 \%$ of adults, four times more frequently than in adolescents.

In the medical college students $\mathrm{HBsAg}$ was not detected, possibly because of the small number of people examined; $\mathrm{HCV}$ was found with the frequency similar to that in schoolchildren. On the other hand, in the medical university students, occurrence rates of hepatitis B and C markers were higher than in other groups.

In conclusion, seroprevalence of $\mathrm{HBV}$ in Novosibirsk is similar to that in central Russia; however, prevalence of $\mathrm{HCV}$ is higher that in the European part of Russia, especially among males.

Prevalence rates of viral hepatitis markers in the general population are 2-2.5 times higher than in blood donors. Blood donors could not serve as a basis for assessment of viral hepatitis prevalence in the community.

Medical students in last grades represent a risk group for the acquisition of the viral hepatitis infections.

OLEG V RESHETNIKOV
Institute of Internal Medicine, Novosibirsk, Russia 
A statement such as: "Some genital wart infections are associated with cancer, as is Chlamydia" may contribute to the anxiety that constitutes much of the burden of morbidity which such mostly innocuous conditions often engender. ${ }^{2}{ }^{3}$ The proposed target to increase uptake of HIV testing in GUM clinics may increase HIV neurosis. Offering an HIV test on first screening may lead to false reassurance and increase the chance of undiagnosed HIV infection, since many patients attend within three months of sexual exposure. The unlinked anonymous HIV prevalence survey ${ }^{4}$ has shown little change in the rate of undiagnosed HIV infection in heterosexuals attending GUM clinics between 1990 and 1999. The most recent (1999) rate in heterosexual men outside London is $0.09 \%$. Increasing the uptake of HIV tests to $60 \%$ by the end of 2007 may miss this tiny fraction; the total number of undiagnosed samples from heterosexual men outside London in 1999 was only 14. Efforts by increasingly stretched professionals in sexual health services to meet targets set by the strategy will result in less energy and time available for more appropriate approaches to the burden of sexually related morbidity.

H BIRLEY

Glenfield, Cathedral Close Cardiff CF5 2ED UK

1 The national strategy for sexual health and HIV DoH 2001.

2 Duncan B, Hart G. Scoular A, Bigrigg A. Qualitative analysis of psychosocial impact of diagnosis of Chlamydia trachomatis: implications for screening. BMF 2001;322:195-9.

3 Birley HDL. Continuing medical ignorance: modern myths in the management of genital warts. Int f STD \& AIDS 2001;12:71-4.

4 Unlinked anonymous prevalence monitoring programme annual report to end of 1999 . http://www.phls.co.uk

Accepted for publication 9 October 2001

\section{NOTICES}

International Herpes Alliance and International Herpes Management Forum

The International Herpes Alliance has introduced a website (www.herpesalliance.org) from which can be downloaded patient information leaflets. Its sister organisation the International Herpes Management Forum (website: www.IHMF.org) has launched new guidelines on the management of herpesvirus infections in pregnancy at the 9th International Congress on Infectious Disease (ICID) in Buenos Aires.
Pan-American Health Organization, regional office of the World Health Organization

A catalogue of publications is available online (www.paho.org). The monthly journal of PAHO, the Pan American Journal of Public Health, is also available (subscriptions: pubsvc@tsp.sheridan.com).

41st St Andrew's Day Festival Symposium on Therapeutics, 6-7 December 2001, Royal College of Physicians of Edinburgh

Further details: Ms Eileen Strawn, Symposium Co-ordinator (tel: 0131225 7324; fax: 0131220 4393; email: e.strawn@rcpe.ac.uk; website: www.rcpe.ac.uk).

International Conference on HIVIAIDS 16-19 December 2001, Mumbai, India

Further details: Dr Chander P Puri, President, Indian Society for Study of Reproduction and Fertility, Institute for Reserach in Reproduction, Jehangir Merwanji Street, Parel, Mumbai 400012, India (tel: 4137730 (Direct), 4132111-2-6-7; fax: 091-0224964853 or 091-022-4139412; email: vichin@

bom4.vsnl.net.in OR dirirr@vsnl.com).

Second International Conference on Sexual Health, to be held in Bangkok, Thailand on 23-28 February 2002

Further details: European Secretariat, Dr Richard Burack (tel: +44 (0) 208599 8029; email: siamcare@aol.com).

7th Congress of the European Society of Contraception, "Changing attitudes to contraception and reproductive health," Genoa, Italy, 10-13 April 2002

Further details: ESC Central Office, OrgaMed, Essenestraat 77, B-1740 Ternat, Belgium (tel: +32 258208 52; fax: +32 258255 15; email: orgamed@village.uunet.be).

MSSVD course in STIs and HIV, at the Institute for Materials, 1 Carlton House Terrace, London, Module 1, Epidemiology of STIs and Bacterial Infections, 22-25 April 2002

Further details: Sue Bird, MSSVD STIs and HIV Course Secretariat, PO Box 77, East Horsley, KT24 5YP (tel: 01372 454210).

MSSVD course in STIs and HIV, at the Institute for Materials, 1 Carlton House Terrace, London, Module 2, Sexual Health and Sexuality, 26 April 2002 Further details: Sue Bird, MSSVD STIs and HIV Course Secretariat, PO Box 77, East Horsley, KT24 5YP (tel: 01372 454210).
MSSVD course in STIs and HIV, at the Institute for Materials, 1 Carlton House Terrace, London, Module 3, Viral Infections other than HIV, 20-21 May 2002 Further details: Sue Bird, MSSVD STIs and HIV Course Secretariat, PO Box 77, East Horsley, KT24 5YP (tel: 01372 454210).

MSSVD course in STIs and HIV, at the Institute for Materials, 1 Carlton House Terrace, London, Module 4, HIV Infections, 22-24 May 2002

Further details: Sue Bird, MSSVD STIs and HIV Course Secretariat, PO Box 77, East Horsley, KT24 5YP (tel: 01372 454210).

10th International Symposium on Human Chlamydial Infection, 16-21 June 2002, in Antalya, Turkey

The scientific programme will encompass the breadth of chlamydial research from clinical and epidemiological studies to molecular and cell biology of all species of Chlamydia. Further details: Professor A Demir Serter, Department of Clinical Microbiology and Infectious Diseases, Ege University, Faculty of Medicine, 35100 Bornova, Izmir, Turkey (fax: 9023234371 30; email: ISHCIX@ itsa.ucsf.edu)

10th International Congress on Behçet's Disease, Berlin 27-29 June 2002

Further details: Professor $\mathrm{Ch}$ Zouboulis (email: zoubbere@zedat.fu-berlin.de).

20th World Congress of Dermatology, Paris, 1-5 July 2002

Further details: P Fournier, Colloquium, 12 rue de la Croix St Faubin, 75011 Paris, France (tel: +331 446415 15; fax: +33144 6415 16; email: p.fournier@colloquium.fr; website: www.derm-wcd-2002.com).

\section{Correction}

Barnett SD, Brundage JF. Incidence of recurrent diagnoses of Chlamydia trachomatis genital infections among male and female soldiers of the US army. Sex Transm Inf 2001;77:33-36.

On page 34 of the article, the authors state that reports of $C$. Trachomatis genital infections were confirmed with "Transcription Mediated Amplification" (GenProbe, San Diego, USA). For this study, cases were ascertained from notifiable medical event case reports from US military medical treatment facilities worldwide. The case reports did not document the specific tests that were used to confirm each diagnosis. The authors regret this error and any confusion it may have caused. 